\title{
IMPLIKASI RELATIONSHIP MARKETING TERHADAP TINGKAT LOYALITAS DEBITUR KREDIT KOMERSIAL
}

\author{
Muhammad Taufiq \\ Universitas Islam Negeri Alauddin Makassar \\ akhtarfifi@gmail.com
}

\section{Keywords: \\ Financial Bonds, Social \\ Bonds, Customization \\ Bonds, Structural Bonds, and Loyalty}

\section{Kata Kunci:}

Financial Bonds, Social Bonds, Customization Bonds, Structural Bonds, dan Loyalitas

\begin{abstract}
Relationship Marketing Strategies (Financial Bonds, Social Bonds, Customization Bonds, and Structural Bonds) are seen as important factors that influence the level of loyalty of commercial credit borrowers. The purpose of this study is to determine the dominant factors in Relationship Marketing, and which Relationship Marketing strategies have the dominant influence on the level of loyalty of commercial credit debtors. The population of the study is all debtors of commercial credit debtor of PT. Bank Rakyat Indonesia (Persero), Tbk. Somba Opu Branch Office comprising 365 debtors. They are selected by stratified random sampling of 80 respondents. The data are analyzed by linier multiple regression. Based on the results of the t-test analysis performed, it was found that the Customization Bonds variable had the most powerful (dominant) influence on the level of loyalty of the commercial credit debtors of PT. Bank Rakyat Indonesia (Persero) Tbk. Makassar Somba Opu Branch Office, then followed successively by Structural Bonds, Financial Bonds, and Social Bonds.
\end{abstract}

\begin{tabular}{l} 
ABSTRAK \\
\hline Strategi Relationship Marketing (Financial Bonds, Social Bonds, \\
Customization Bonds, dan Structural Bonds) dipandang sebagai faktor \\
penting yang berpengaruh terhadap tingkat loyalitas debitur kredit \\
komersial. Tujuan dari studi ini adalah untuk mengetahui faktor \\
yang dominan dalam Relationship Marketing, dan strategi Relationship \\
Marketing mana yang berpengaruh dominan terhadap tingkat \\
loyalitas debitur kredit komersial.Populasi penelitian ini adalah \\
seluruh debitur kredit komersial PT. Bank Rakyat Indonesia \\
(Persero), Tbk. Kantor Cabang Makassar Somba Opu sebanyak 365 \\
debitur. Sampel dipilih secara acak berstrata sebanyak 80 \\
responden. Data dianalisis dengan regresi linier berganda. \\
Berdasarkan hasil analisis Uji t yang dilakukan, didapatkan hasil \\
bahwa variabel Customization Bonds memberikan pengaruh paling \\
kuat (dominan)terhadap tingkat loyalitas debitur kredit komersial \\
PT. Bank Rakyat Indonesia (Persero) Tbk. Kantor Cabang \\
Makassar Somba Opu, kemudian diikuti berturut-turut oleh \\
Structural Bonds, Financial Bonds, dan Social Bonds.
\end{tabular}

\section{PENDAHULUAN}

Dengan semakin tingginya tingkat persaingan bisnis, telah mengalihkan perhatian banyak perusahaan penyedia jasa (service provider) untuk lebih menekankan pada upaya untuk mempertahankan pelanggan (retensi pelanggan) yang sudah ada daripada mengakuisisi pelanggan baru. Mempertahankan pelanggan yang sudah ada akan memerlukan biaya pemasaran lebih kecil sebesar 25\% dari biaya untuk mengakuisisi pelanggan baru (Penelitian Clancy \& Shulman, 1994). Selain itu, penciptaan retensi pelanggan (customer retention) 
sebesar 5\% juga terbukti dapat meningkatkan laba jangka panjang perusahaan sebesar $25 \% \mathrm{~s} / \mathrm{d}$ 95\% (Reicheld \& Sasser, 1990). Retensi pelanggan tersebut juga memiliki arti penting bagi industri perbankan karena berkontribusi terhadap kelangsungan hidup perusahaan. Upaya untuk meningkatkan retensi pelanggan dapat dilakukan dengan penciptaan rintangan beralih ke pesaing (switch barrier) yang tinggi, dan memuaskan pelanggan melalui pembinaan relasi yang intim (close relationship) dengan pelanggan, yang diyakini berpengaruh positif terhadap kesetiaan pelanggan terhadap penyedia jasa.

Upaya untuk meningkatkan retensi pelanggan berupa pembinaan relasi yang intim (close relationship) dengan pelanggan, dapat dilakukan dengan mengubah paradigma lama perusahaan dalam strategi pemasaran, yakni dari pola pendekatan transaksional (transactional approach) beralih kepada pola pendekatan relasional (relationship approach).

Konsep pemasaran dengan pendekatan transaksional yang selama ini digunakan oleh banyak perusahaan, telah menyebabkan perusahaan hanya berkonsentrasi pada upaya-upaya untuk mendapatkan pelanggan baru sebanyak-banyaknya bagi keberhasilan penjualan produk mereka tanpa dibarengi dengan upaya penciptaan customer retention. Akibatnya pelanggan banyak ditemukan beralih karena program pemasaran yang dilakukan oleh perusahaan hanya bersifat transaksional semata sehingga perusahaan tidak memiliki pelanggan yang loyal.

Sedangkan konsep pemasaran dengan pendekatan relasional memberikan penekanan pada upaya penciptaan retensi pelanggan melalui pembinaan hubungan jangka panjang (tingkat kualitas relasi) dengan pelanggan yang sudah ada sehingga perusahaan dapat memiliki pelanggan yang loyal. Pendekatan relasional ini diharapkan mampu menjadi senjata yang ampuh bagi setiap perusahaan yang ingin tetap eksis dalam persaingan bisnis di masa yang akan datang.

PT. Bank Rakyat Indonesia (Persero) Tbk. Kantor Cabang Makassar Somba Opu mulai beroperasi pada tgl. 7Agustus 1989, hadir sebagai tuntutan dari perkembangan sektor ekonomi yang semakin meningkat di Makassar, dan hingga saat ini (bulan Februari 2007) jumlah debitur kredit komersial sebanyak 365 debitur yang terdiri dari plafond kredit s/d 100 Jt sebanyak 23 debitur, $100 \mathrm{Jt}$ s/d $350 \mathrm{Jt}$ sebanyak 179 debitur, $350 \mathrm{Jt} \mathrm{s} / \mathrm{d} 500 \mathrm{Jt}$ sebanyak 45 debitur, $500 \mathrm{Jt}$ s/d 1 M sebanyak 60 debitur, dan diatas 1 M sebanyak 58 debitur.

Dengan menerapkan konsep Relationship Marketing, diharapkan agar debitur Bank Rakyat Indonesia. Kantor Cabang Makassar Somba Opu dapat terbangun hubungan yang bersifat jangka panjang yang akan meningkatkan tingkat retensi debitur. Dengan demikian, debitur akan semakin loyal dan percaya dan pada akhirnya akan memberikan kontribusi baik bagi kinerja PT. Bank Rakyat Indonesia (Persero) Tbk. Kantor Cabang Makassar Somba Opu.

Adapun tujuan dari penelitian iniadalah:1) Untuk mengetahui pengaruh strategi Relationship Marketing terhadap tingkat loyalitas debitur kredit komersial PT. Bank Rakyat Indonesia (Persero) Tbk. Kantor Cabang Makassar Somba Opu. 2)Untuk mengetahui strategi Relationship Marketing mana yang memiliki pengaruh dominan terhadap tingkat loyalitas debitur kredit komersial PT. Bank Rakyat Indonesia (Persero) Tbk. Kantor Cabang Makassar Somba Opu.

\section{LANDASAN TEORI}

Definisi kredit menurut Undang-Undang Pokok Perbankan No. 7 Tahun 1992, "Kredit adalah penyediaan uang atau tagihan yang dipersamakan dengan itu, berdasarkan persetujuan atas kesepakatan pinjam meminjam antara bank dengan pihak lain yang mewajibkan pihak peminjam untuk melunasi hutangnya setelah jangka waktu tertentu dengan sejumlah hubungan imbalan atau pembagian hasil keuntungan". 
Pengelompokan kredit di BRI

Pengelompokan kredit berdasarkan jangka waktu :

- Kredit Jangka Pendek $(\leq 1 \mathrm{Thn})$

- Kredit Jangka Menengah (1 Thn $<$ Kredit $\leq 3$ Thn)

- Kredit Jangka Panjang (> 3 Thn)

Pengelompokan kredit berdasarkan segmen bisnis :

- Kredit Mikro / Kupedes (s/d 100 Jt)

- Kredit Program (s/d 50 Jt)

- Kredit Retail (Komersial dan Konsumtif) (s/d 5 M), al. :

- Kredit Modal Kerja (KMK)

- Kredit Investasi (KI)

- Menengah (eksposur > Rp5 M s/d Rp50 M)

- Korporasi (eksposur > Rp50 M)

Pada era sebelum Relationship Marketing (RM), value dan brand merupakan dua faktor utama yang menjadi perangsang bagi terjadinya initial purchase, dan sekaligus menjadi pendorong terjadinya repetition purchase. Perkembangan yang terjadi saat ini, memberikan kesadaran di benak para pemasar bahwa loyalitas pelanggan tidak bisa diperoleh hanya dengan mengandalkan value and brand.

Loyalitas pelanggan harus dibangun dengan usaha keras dalam bentuk personalisasi, customize marketing program atau disebut juga dengan one-to-one marketing. Oleh sebab itu, untuk menjamin terjadinya repetition purchase dari pelanggan yang sama, konsep 2 pilar (value dan brand) berkembang menjadi 3 pilar (value, brand, Relationship Marketing) dengan penempatan pelanggan pada sentral semua aktivitas pemasaran.

\section{Gambar 1. Pilar Loyalitas Pelanggan}

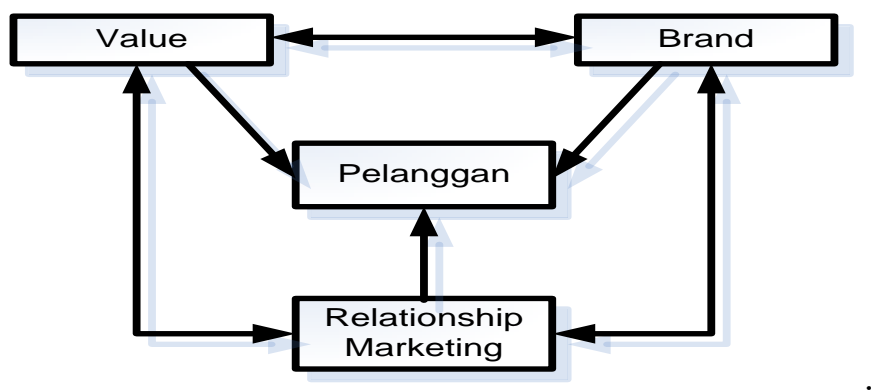

Sumber :Syafruddin Chan, 2003

Pertama, Value, adalah persepsi nilai yang dimiliki oleh pelanggan berdasarkan apa yang didapat dan apa yang dikorbankan dalam melakukan transaksi. Semakin besar perolehan nilai yang didapatkan seseorang dibandingkan pengorbanan yang dilakukan, maka akan semakin besar kepuasan yang didapatnya dan semakin tinggi value yang didapat dari transaksi tersebut.

Kedua, Brand, adalah identitas sebuah produk. Tanpa brand, sebuah produk akan masuk dalam kategori komoditas. Brand merupakan asset perusahaan yang tak terlihat, tetapi sangat bernilai. Contohnya adalah Coca-Cola yang dikenal oleh semua orang. Brand menjadi penting sebagai alat untuk mengidentifikasi produk tertentu, untuk membedakan produknya 
dengan produk sejenis dari pesaing, untuk keperluan transaksi, baik dengan dealer, retailer, maupun danuser, serta berfungsi sebagai alat memenangkan persaingan (share of mind).

Ketiga, Relationship Marketing, didefinisikan sebagai pengenalan setiap pelanggan secara lebih dekat dengan menciptakan komunikasi dua arah dengan mengelola suatu hubungan yang saling menguntungkan antara pelanggan dan perusahaan.

Dalam konsep Relationship Marketing, pemasar harus mengetahui keinginan-keinginan yang khas (unique need), preferensi, gaya hidup, dan hobi pelanggan, sehingga pelanggan merasa tidak membeli sesuatu dari orang asing. Ia membeli dari seseorang yang telah kenal betul dengan dirinya, dengan keluarganya, bahkan dengan teman-temannya.

Dalam bukunya Total Relationship Marketing, Gummesson (1999) mengidentifikasi 30 kemungkinan relasi yang dinamakannya 30R sebagaimana tersaji dalam tabel 2.1 hal.23-24. Sejauh ini, literatur RM banyak dijumpai dalam konteks pemasaran jasa dan pemasaran bisnis (business-to-business marketing). Shani \& Chalasani (1993), misalnya. mendefinisikan RM sebagai upaya mengembangkan relasi berkesinambungan dengan pelanggan dalam kaitannya dengan serangkaian produk dan jasa terkait. Gronroos (19VC memandang RM sebagai upaya mengembangkan, mempertahankan, meningkatkan, mengomersialisasikan relasi pelanggan dalam rangka mewujudkan tujuan semua pihak yang terlibat.

Lebih lanjut, Morgan \& Hunt (1994) lebih berfokus pada perspektif relational exchanges dan merumuskan RM sebagai segala aktivitas pemasaran yang diarahkan pada membangun, mengembangkan, dan mempertahankan pertukaran relasional yang sukses. Berdasarkan perspektif, Morgan \& Hunt (1994) mengklasifikasikan sepuluh macam kategori pertukaran relasional yang dikelompokkan dalam supplier, lateral, buyer, dan internal partnerships.

Berbeda halnya dengan transaction marketing yang lebih berorientasi pada transaksi penjualan jangka pendek, relationship marketing lebih menekankan pentingnya jalinan kerjasama yang saling menguntungkan dengan pelanggan dalam jangka panjang. Untuk itu, dibutuhkan strategi, kinerja, kompetensi inti, sumber daya (manusia, alam, financial, teknologi, intelektual, informasi, dan waktu), dan koordinasi. Selain itu, diperlukan sinergi antarfungsi dalam organisasi demi penciptaan nilai bagi terwujudnya kepuasan dan loyalitas pelanggan.

Tabel 1. Transaction Marketing VS Relationship Marketing

\begin{tabular}{|c|c|}
\hline Transaction marketing & Relationship marketing \\
\hline Berfokus pada penjualan tunggal & $\begin{array}{l}\text { Berfokus pada upaya menjalin hubungan } \\
\text { jangka panjang dengan pelanggan. }\end{array}$ \\
\hline Menyamaratakan semua pelanggan & $\begin{array}{l}\text { Pelanggan bersifat unik dan tidak identik satu } \\
\text { sama lain. }\end{array}$ \\
\hline $\begin{array}{l}\text { Memanipulasi bauran pemasaran untuk } \\
\text { memaksimumkan penjualan dan } \\
\text { profitabilitas. }\end{array}$ & $\begin{array}{l}\text { Menekankan serangkaian transaksi sepanjang } \\
\text { waktu }\end{array}$ \\
\hline Berfokus pada industri & Berfokus pada jejaring (network) \\
\hline Lebih banyak didasarkan pada ekonomis & $\begin{array}{l}\text { Lebih banyak didasarkan pada psikologi dan } \\
\text { sosiologi }\end{array}$ \\
\hline Berorientasi pada karakteristik produk & Berorientasi pada manfaat produk \\
\hline $\begin{array}{l}\text { Tanggung jawab utama atas kualitas produk } \\
\text { diemban departemen produksi }\end{array}$ & $\begin{array}{l}\text { Kualitas merupakan tanggung jawab semua } \\
\text { anggota organisasi. }\end{array}$ \\
\hline
\end{tabular}

Relationship marketing menekankan upaya menjalin hubungan yang kuat antara organisasi dan semua pasar stakeholder-nya. Christopher, Payne \& Ballantyne (2002) mengidentifikasi enam pasar stakeholder utama yang mempengaruhi efektivitas pemasaran organisasi, yakni : 


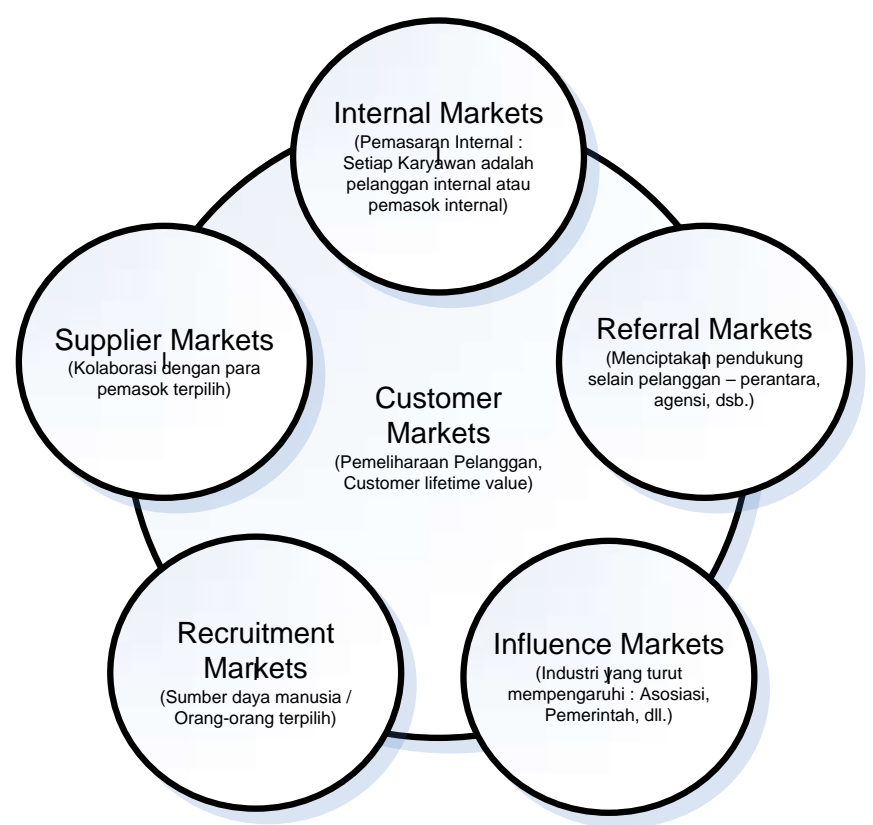

Gambar 2. Pasar StakeholderChristopher, Payne \& Ballantyne (2002)

Pertama,Customer markets (pasar pelanggan) terdiri atas pembeli (pedagang grosir), perantara (pengecer), dan konsumen akhir (end user). Kedua,Influence markets meliputi berbagai pihak, seperti financial and investor influence markets, environmental influence markets, competitor influence markets, dan political and regulatory influence markets. Ketiga,Recruitment markets (pasar rekrutmen) bisa berupa agen penyalur tenaga kerja, headhunters firms, universitas, transfer internal, dan sebagainya. Keempat Supplier markets (pasar pemasok/aliansi) berupa pihak-pihak yang memasok sumber daya fisik (seperti bahan mentah, komponen, produk, atau tangible items lainnya). Termasuk pula dalam tipe dasar ini adalah para mitra aliansi yang menyediakan komperensi dan kapabilitas berbasis pengetahuan dan bukan sekadar berbasis produk. Kelima,Internal markets (pasar internal) adalah setiap karyawan dan departemen dalam organisasi yang sama. Keenam, Referral markets meliputi dua kategori utama, yakni

1. Customer referral sources, : advocacy referral (konsumen sendiri yang berinisiatif untuk merekomendasikan produk dan jasa organisasi kepada pihak lain) dan customerbase development (customer referral yang distimulasi oleh perusahaan melalui serangkaian aktivitas atau program khusus, seperti insentif yang ditawarkan kepada pelanggan saat ini agar mereka merekomendasikan produk dan jasa organisasi kepada orang lain)

2. Non-customer referral sources : referral yang dilakukan oleh staf dan pihak ketiga, diklasifikasikan menjadi general referrals (terdiri atas professional referrals, expertise referrals, specification referrals, dan substitute and complementary referrals), reciprocal referrals, incentive-based referrals, and staff referrals.

Meskipun keenam pasar ini saling berkairan erat, tingkat kepentingannya berbeda beda tiap perusahaan. Oleh sebab itu, setiap perusahaan perlu menentukan tipe pasar yang paling relevan baginya.Menurut (Gwinner, Gremler \& Bitner, 1998), manfaat RM bagi pelanggan meliputi :

1. Confidence benefits; merupakan manfaat berupa keyakinan atau trust terhadap penyedia jasa dan berkurangnya ketidakpastian menyangkut kinerja yang akan diterima. Dengan mempertahankan relasi dengan penyedia jasa tertentu yang telah 
Muhammad Taufiq. Implikasi Relationship Marketing...

dikenal baik, pelanggan bisa terbebas dari biaya pencarian (search costs) saat membutuhkan jasa bersangkutan.

2. Social benefits; berkaitan dengan familiaritas dan relasi sosial antara pelanggan dan penyedia jasa. Dalam berbagai kasus, pelanggan dan penyedia jasa bisa menjadi sahabat karib, misalnya antara penata rambut dan pelanggan; pelatih renang dan perenang dan sebagainya. Ikatan sosial yang terbina dengan baik akan menjadi switching barrier yang efektif. Bahkan, ketika pelanggan mendapati bahwa ada penyedia jasa lain yang menawarkan kualitas lebih baik atau harga lebih murah.

3. Special treatment benefits; berwujud harga khusus, penawaran spesial dan perlakuan istimewa kepada pelanggan spesial.

Manfaat-manfaat langsung ini berkontribusi pada marjin yang lebih besar dan pada gilirannya meningkatkan profitabilitas perusahaan. Riset yang dilakukan Bain\& Co. menunjukkan bahwa dampak peningkatan 5\% pada tingkat retensi atau loyalitas pelanggan terhadap persentase peningkatan laba total perusahaan di sejumlah industri adalah sebagai berikut (Reichheld, 1994). Biro periklanan (peningkatan laba 95\%), penerbitan (85\%), asuransi mobil dan rumah (84\%), reparasi mobil (8 1\%), jasa kartu kredit (75\%), distribusi industrial (45\%), dan perangkat lunak $(35 \%)$.

Menurut Zeithami \& Bitner (2003), terdapat tiga faktor kunci sukses implementasi RM, yakni:Pertama, Kualitas jasa inti, Bila kualitas jasa inti tidak memenuhi standar, maka akan sulit bagi organisasi jasa untuk menjalin relasi yang langgeng dengan para pelanggannya. Kedua Segmentasi dan pemilihan pasar sasaran secara cermat. Segmentasi (demografis, geografis, psikografis dan/atau behavioral) sesuai dengan kriteria measurability, accessibility, substantiality, dan actionability. Ketiga,Pemantauan berkesinambungan terhadap relasi yang dibina dilakukan dengan melakukan survei reguler untuk memahami persepsi pelanggan terhadap nilai yang diterima, kualitas, kepuasan terhadap layanan perusahaan. Faktor kunci sukses tersebut menjadi fondasi bagi pemilihan level strategi relasi yang relevan bagi organisasi, sebagaimana tersaji dalam Tabel 2. sebagai berikut:

Tabel 2. Variabel RM

\begin{tabular}{ll}
\hline Financial Bonds & Volume and Frequency Rewards \\
& Bundling and Cross Selling \\
& Stable Pricing \\
Social Bonds & Continuous Relationships \\
& Personal Relationships \\
& Social Bonds among Customers \\
& Customer Intimacy \\
Customization Bonds & Mass Customization (MC) \\
& Antiripation / Innovation \\
Structural Bonds & Shared Proses and Equipment \\
& Joint Investment \\
& Integrated Information System \\
\hline
\end{tabular}

Sumber :Zeithami \& Bitner (2003)

Menurut Oliver (1996 : 392) loyalitas pelanggan adalah komitmen pelanggan bertahan secara mendalam untuk berlangganan kembali atau melakukan pembelian ulang produk / jasa terpilih secara konsisten di masa yang akan datang, meskipun pengaruh situasi dan usaha-usaha pemasaran mempunyai potensi untuk menyebabkan perubahan perilaku.

Menurut Griffin (2004 : 4), dijelaskan bahwa loyalitas lebih mengacu pada wujud perilaku dari unit-unit pengambilan keputusan untuk melakukan pembelian secara terus 
menerus terhadap barang / jasa suatu perusahaan yang dipilih. Keuntungan yang akan diperoleh perusahaan apabila memiliki pelanggan yang loyal, antara lain :

1) Dapat mengurangi biaya pemasaran (karena biaya untuk menarik pelanggan yang baru lebih mahal).

2) Dapat mengurangi biaya transaksi

3) Dapat mengurangi biaya turn over konsumen (karena penggantian konsumen yang lebih sedikit)

4) Dapat meningkatkan penjualan silang, yang akan memperbesar pangsa pasar perusahaan

5) Mendorong word of mouth yang lebih positif

6) Dapat mengurangi biaya kegagalan (seperti biaya penggantian)

Karakteristik Loyalitas Pelanggan menurut Griffin (2002 : 31) :

a) Melakukan pembelian secara teratur (makes regular repeat purchases)

b) Membeli di luar lini produk / jasa (purchase across product and service lines)

c) Merekomendasikan produk lain (refers other)

d) Menunjukkan kekebalan dari daya tarik produk sejenis dari pesaing (Demonstrates an immunity to the full of the competition).

Tahapan loyalitas menurut Niegel Hill. Menurut Hill (1996:60) :

\section{Gambar 3. Piramida Loyalitas}

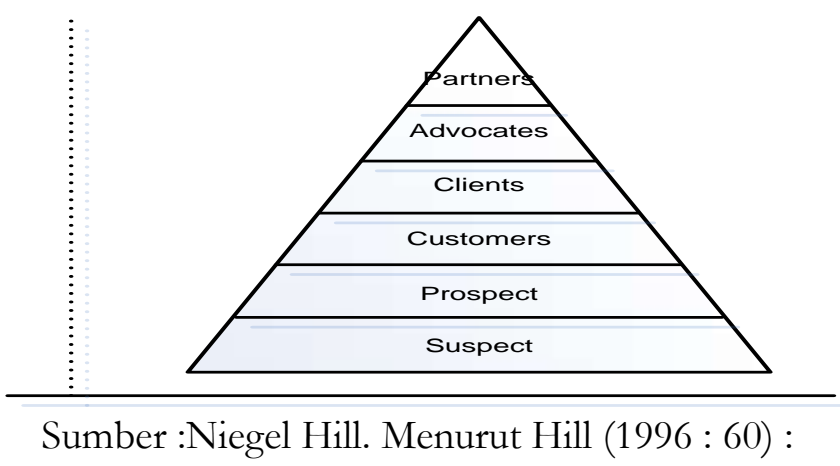

a) Suspect, meliputi semua orang yang diyakini akan membeli (membutuhkan) barang / jasa, tetapi belum memiliki informasi tetntang barang / jasa perusahaan.

b) Prospect, adalah orang yang memiliki kebutuhan akan jasa tertentu, dan mempunyai kemampuan untuk membelinya. Pada tahap ini, meskipun mereka belum melakukan pembelian tetapi telah mengetahui keberadaan perusahaan dan jasa yang ditawarkan melalui rekomendasi pihak lain (word of mouth).

c) Customers, pada tahap ini pelanggan sudah melakukan hubungan transaksi dengan perusahaan, tetapi tidak mempunyai perasaan positif terhadap perusahaan. Loyalitas pada tahap ini belum terlihat.

d) Clients, meliputi semua pelanggan yang telah membeli barang / jasa yang dibutuhkan dan ditawarkan perusahaan secara teratur. Hubungan ini berlangsung lama, dan mereka telah memiliki sifat retention.

e) Advocates, pada tahap ini clients secara aktif mendukung perusahaan dengan memberikan rekomendasi kepada orang lain agar mau membeli barang / jasa di perusahaan tersebut.

f) Partners, pada tahap ini telah terjadi hubungan yang kuat dan saling menguntungkan antara perusahaan dengan pelanggan. Pada tahap ini pula pelanggan berani menolak produk / jasa dari perusahaan lain. 


\section{METODE PENELITIAN}

Jenis penelitian yang digunakan dalam penelitian ini yaitu jenis penelitian kuantitatif, dengan pendekatan eksplanatori yakni penelitian yang menjelaskan hubungan kausal antara variabel-variabel yang mempengaruhi hipotesis. Pada penelitian ini minimal terdapat dua variabel yang dihubungkan dan penelitian ini berfungsi menjelaskan, meramalkan, dan mengontrol suatu gejala. Oleh karena itu dalam penelitian ini nantinya akan dijelaskan mengenai adanya hubungan interaktif atau timbal balik antara variabel yang akan diteliti dan sejauh mana hubungan tersebut saling mempengaruhi.Tipe penelitian ini umumnya berkaitan dengan opini (individu, kelompok atau organisasional), kejadian atau prosedur (Indriantoro dan Supomo, 2013).

Populasi dalam penelitian ini adalah selurah debitur kredit komersial PT. Bank Rakyat Indonesia (Persero) Tbk. Kantor Cabang Makassar Somba Opu.Teknik pengambilan sampel melalui metode probabilitas dengan cara pemilihan sampel acak berdasarkan strata (Stratified Random Sampling) secara disproporsional, yaitu dilakukan dengan terlebih dahulu mengklasifikasi suatu populasi ke dalam sub-sub populasi berdasarkan karakteristik besar plafond kredit yang diberikan.

Berdasarkan data debitur kredit komersial PT. Bank Rakyat Indonesia (Persero) Tbk. Kantor Cabang Makassar Somba Opu pada akhir bulan Februari 2007, jumlah masing-masing strata debitur kredit komersial berdasarkan besar plafond kredit adalah sebagai berikut:
a. s/d $100 \mathrm{Jt}$
: 23 debitur
b. $100 \mathrm{Jt} \mathrm{s} / \mathrm{d} 350 \mathrm{Jt} \quad: 179$ debitur
c. $350 \mathrm{Jt} \mathrm{s} / \mathrm{d} 500 \mathrm{Jt} \quad$ : 45 debitur
d. $500 \mathrm{Jt} \mathrm{s} / \mathrm{d} 1 \mathrm{M} \quad$ : 60 debitur
e. $>1 \mathrm{M} \quad$ : 58 debitur
f. Total debitur : 365 debitur

Dengan demikian, jumlah sampel yang diambil adalah sebagai berikut :

Tabel 3. Jumlah Sampel

\begin{tabular}{lcc}
\hline \multicolumn{1}{c}{ Strata } & Jumlah Strata & Jumlah Sampel \\
\hline s/d 100 Jt & 23 & 2 \\
$100 \mathrm{Jt} \mathrm{s} / \mathrm{d}$ 350 Jt & 179 & 18 \\
$350 \mathrm{Jt} \mathrm{s} / \mathrm{d} 500 \mathrm{Jt}$ & 45 & 12 \\
$500 \mathrm{Jt} \mathrm{s} / \mathrm{d}$ 1 M & 60 & 20 \\
$>1 \mathrm{M}$ & 58 & 28 \\
\hline Total & $\mathbf{3 6 5}$ & $\mathbf{8 0}$ \\
\hline
\end{tabular}

Sumber : PT. Bank Rakyat Indonesia (Persero) Tbk. Kantor Cabang Makassar Somba Opu (diolah). Tahun 2017

Dengan menggunakan rumus Slovin (Sevilla : 160) adalah sbb. :

$$
\begin{aligned}
& \qquad n=\frac{N}{1+N e^{2}} \\
& \mathrm{n}=\text { Ukuran sampel } \\
& \mathrm{N}=\text { Ukuran populasi } \\
& \mathrm{e}=\text { nilai kritis (batas ketelitian) } \\
& \text { Hasilnya, } n=78,49 \text { (dibulatkan } 80 \text { sampel) }
\end{aligned}
$$

Analisis statistik yang digunakan dalam penelitian ini adalah "Analisis Regresi Berganda" dengan menggunakan program SPSS, yang digunakan untuk menguji ada tidaknya 
pengaruh Relationship Marketing terhadap tingkat loyalitas debitur kredit komersial PT. Bank Rakyat Indonesia (Persero) Tbk. Kantor Cabang Makassar Somba Opu.

Rumus yang digunakan adalah :

$$
Y=\alpha+\beta_{1} X_{1}+\beta_{2} X_{2}+\beta_{3} X_{3}+\beta_{4} X_{4}
$$

Keterangan :

$\mathrm{Y}=$ Tingkat Loyalitas

$\alpha=$ Konstanta Intersepsi

$\beta=$ Koefisien Regresi

$\mathrm{X}_{1}=$ Financial Bonds

$\mathrm{X}_{2}=$ Social Bonds

$\mathrm{X}_{3}=$ Customization Bonds

$\mathrm{X}_{4}=$ Structural Bonds

Data yang berhasil dikumpulkan dari kuesioner selanjutnya akan diukur dengan pengukuran data original dengan bobot hitung 1 sampai 5. Pada metode ini, Relationship Marketing dan loyalitas debitur dinilai berdasarkan indikator-indikator dari kedua variabel di atas. Metode pengukuran untuk variabel Relationship Marketing dinilai dengan kategori sangat bagus dengan nilai 5 , bagus dengan nilai 4 , kuarang bagus dengan nilai 3 , tidak bagus dengan nilai 2, dan sangat tidak bagus dengan nilai 1 . Sedangkan loyalitas debitur diukur dengan kategori sangat loyal dengan nilai 5 , loyal dengan nilai 4, kurang loyal dengan nilai 3 , tidak loyal dengan nilai 2, dan sangat tidak loyal dengan nilai 1.

Uji Validitas dan Uji Reliabilitas Instrumen Penelitian

Uji Validitas menunjukkan seberapa jauh instrumen dapat digunakan untuk mengukur apa yang seharusnya diukur atau apa yang diharapkan (Sugiyono : 1999), dan dilakukan dengan menggunakan metode Pearson's Product Moment Correlation.

Uji Reliabilitas dilakukan untuk mengetahui sampai sejauh mana suatu instrument dapat dipercaya atau dapat diandalkan. Pengujian dilakukan dengan uji reliabilitas konsistensi internal dengan menggunakan Cronbach's Alpha.

Variabel bebas (independent) adalah level strategi relationship marketing (RM) dimana parameternya terdiri dari Financial Bonds, Social Bonds, Customization Bonds, Structural Bonds.

Tabel 4. Variabel bebas

\begin{tabular}{cll}
\hline Variabel & \multicolumn{1}{c}{$\begin{array}{c}\text { Parameter Kinerja } \\
\text { Relationship Marketing }\end{array}$} & \multicolumn{1}{c}{ Indikator-indikator } \\
\hline \multirow{2}{*}{$\mathrm{X}_{1}$} & Financial Bonds & a. Volume and Frequency Rewards \\
& & b. Bundling and Cross Selling \\
& c. Stable Pricing \\
$\mathrm{X}_{2}$ & Social Bonds & a. Continuous Relationships \\
& & b. Personal Relationships \\
& & c. Social Bonds among Customers \\
& & a. Customer Intimacy \\
$\mathrm{X}_{3}$ & Customization Bonds & b. Mass Customization \\
& & c. Antizipation / Innovation \\
& & a. Shared Proses and Equipment \\
$\mathrm{X}_{4}$ & Structural Bonds & b. Soint Investment \\
& & c. Integrated Information System
\end{tabular}


Muhammad Taufiq. Implikasi Relationship Marketing...

Variabel terikat (dependent) adalah tingkat loyalitas debitur kredit komersial PT. Bank Rakyat Indonesia (Persero) Tbk. Kantor Cabang Makassar Somba Opu.Indikator-indikatornya Hurriyati $(2005: 131-141)$ :

1. Melakukan pembelian secara teratur (dalam hal ini adalah transaksi dan jasa layanan bank)

2. Merekomendasikan produk kepada orang lain

3. Menunjukkan kekebalan dari daya tarik produk sejenis dari pesaing

4. Bersedia membela produk

5. Tidak lagi mempertimbangkan harga, produk, dan bauran pemasaran lainnya.

6. Tingkat kepuasan tinggi.

\section{Financial Bonds}

Level relasi dimana perusahaan berusaha menawarkan insentif finansial kepada pelanggan.

a. Volume and Frequency Rewards

Seperti harga lebih murah untuk pembelian dalam volume besar atau harga lebih murah bagi pelanggan yang telah menjadi langganan selama periode waktu tertentu

b. Bundling and Cross Selling

Penawaran jasa dalam paket tertentu (bundling) dan penjualan silang (cross-selling) dimana memberikan kemudahan dan value for money bagi pelanggan. Seperti yang dilakukan oleh agen perjalanan bekerja sama dengan jaringan hotel, perusahaan penerbangan, persewaan mobil, dan jasa kartu kredit.

\section{c. Stable Pricing}

Yaitu dengan memberikan jaminan kepastian harga yang stabil kepada pelanggan yang paling loyal. Setidaknya bila terjadi kenaikan harga, peningkatannya akan lebih kecil dibandingkan yang dibayarkan oleh pelanggan baru.

2. Social Bonds

Level relasi ini membangun relasi jangka panjang melalui ikatan sosial, interpersonal dan finansial.

\section{a. Continuous Relationships}

Yaitu memperlakukan pelanggan sebagai 'klien' atau individu yang kebutuhan dan keinginannya ingin dipahami dan dipuaskan oleh perusahaan (Konsumen bukan sekadar 'statistik' atau kerumunan orang tidak dikenal).

b. Personal Relationships

Yaitu menjalin hubungan yang interpersonal, seperti yang banyak dipraktikkan oleh para penyedia jasa profesional (seperti pengacara, akuntan, guru, dosen), penyedia jasa personal (contohnya, penata rambut, konselor, dokter), dan business-to-business services (misalnya, antara manajer relasi dan wiraniaga dengan klien).

c. Social Bonds among Customers

Yaitu berusaha menjalin ikatan sosial sesama pelanggan, contohnya Harley Owners Groups (HOG) yang aktif melakukan berbagai aktivitas untuk para anggotanya. Ikatan serupa juga banyak dijumpai pada klub kebugaran, fans clubs, ikatan alumni, country clubs, dan sebagainya, Kendati ikatan sosial mungkin tidak mampu mengikat pelanggan selamanya dengan perusahaan, namun setidaknya ikatan sosial lebih sulit ditiru pesaing dibandingkan ikatan finansial

\section{Customization Bonds}

Level ini menuntut kemampuan organisasi untuk merancang dan menerapkan proses dan struktur organisasi yang fleksibel dalam rangka menghasilkan customized services bagi para pelanggan. 


\section{AL-MASHRAFIYAH: Jurnal Ekonomi, Keuangan, dan Perbankan Syariah}

Volume 2, Nomor 2, Oktober 2018

a. Customer Intimacy

Yaitu membangun loyalitas pelanggan melalui pemahaman mendalam atas pelanggan individual dan menawarkan solusi "one-on-one" yang sesuai dengan kebutuhan individual.

b. Mass Customization (MC)

Yaitu dengan menciptakan produk yang sesuai dengan kebutuhan unik masing-masing pelanggan, dan bahkan pelanggan dapat mengatur sendiri atribut dan parameternya sendiri-sendiri.

\section{c. Antizipation / Innovation}

Yaitu perusahaan senantiasa melakukan inovasi terhadap produk-produknya agar tetap dikonsumsi oleh konsumennya, baik dengan cara mengeluarkan produk-produk baru maupun dengan memperbarui produk-produk lama agar sesuai dengan harapan pelanggan.

4. Structural Bonds

Level relasi ini paling sulit ditiru, karena meliputi ikatan struktural, finansial, sosial, dan customization antara pelanggan dan perusahaan.

a. Shared Proses and Equipment

Yaitu menciptakan penyediaan jasa kepada klien yang dirancang khusus dalam sistem penyampaian jasa kepada klien bersangkutan

b. Joint Investment

Yaitu dengan melakukan pemberdayaan atau pendayagunaan pelanggan melalui sistem investasi bersama (joint investment), misal menanamkan keyakinan dan image / citra yang positif kepada pelanggan sehingga pelanggan merasa nyaman dan bisa merekomendasikan produk / jasa perusahaan ke orang lain.

c. Integrated Information System

Yaitu penyediaan customized services yang berbasis teknologi dan membuat pelanggan lebih produktif. Contohnva adalah Federal Express yang menyediakan komputer gratis (Federal Express's Power Ships) kepada klien-klien utamanya dalam rangka memudahkan pemrosesan dan pelacakan paket kiriman yang ditangani.

\section{HASIL DAN PEMBAHASAN}

\section{A. Analisis Deskriptif Variabel Penelitian}

\section{Variabel Financial Bonds}

Berdasarkan rata-rata penilaian dari 80 responden terhadap ketiga indikator yang menentukan bentuk dari variabel Financial Bonds, terdapat 22 responden (27\%) menyatakan sangat setuju, 46 responden (58\%) menyatakan setuju, 10 responden $(12 \%)$ menyatakan kurang setuju, dan 2 responden $(3 \%)$ menyatakan tidak setuju. Oleh karena itu dapat dibuat kesimpulan bahwa 85\% deitur BRI Somba Opu telah menerima insentif finansial dengan baik, dan sisanya sebesar 15\% debitur masih menganggap insentif finansial yang diberikan kurang baik.Insentif finansial yang diberikan berupa tingkat suku bunga kredit yang lebih rendah, value for money, dan biaya kredit yang tetap / tidak berubah. 
Muhammad Taufiq. Implikasi Relationship Marketing...

\section{Variabel Social Bonds}

Berdasarkan rata-rata penilaian dari 80 responden terhadap ketiga indikator yang menentukan bentuk dari variabel Social Bonds, terdapat 34 responden (43\%) menyatakan sangat setuju, 38 responden (48\%) menyatakan setuju, 6 responden $(8 \%)$ menyatakan kurang setuju, dan 1 responden (1\%) menyatakan tidak setuju. Oleh karena itu dapat dibuat kesimpulan bahwa hubungan sosial yang telah terjalin selama ini antara BRI Somba Opu dengan para debiturnya sangat kuat sebesar 91\%. Sedangkan sisanya sebesar 9\% menunjukkan terdapat hubungan sosial yang cukup renggang yang perlu untuk dicermati dan diperbaiki.

\section{Variabel Customization Bonds}

Berdasarkan rata-rata penilaian dari 80 responden terhadap ketiga indikator yang menentukan bentuk dari variabel Customization Bonds, terdapat 27 responden (34\%) menyatakan sangat setuju, 45 responden (57\%) menyatakan setuju, dan 7 responden $(9 \%)$ menyatakan kurang setuju. Oleh karena itu dapat dibuat kesimpulan bahwa BRI Somba Opu sebesar 91\%dianggap telah mampu merancang, dan membuat produk pinjaman yang cocok (customized services) bagi para debiturnya. Sedangkan sisanya sebesar $9 \%$ menunjukkan terdapat debitur yang belum cocok dan merasa nyaman dengan produk pinjaman BRI Somba Opu. Hal ini perlu dikaji dan di desain ulang agar menghasilkan produk pinjaman yang lebih customized services.

\section{Variabel Structural Bonds}

Berdasarkan rata-rata penilaian dari 80 responden terhadap ketiga indikator yang menentukan bentuk dari variabel Structural Bonds, terdapat 34 responden (43\%) menyatakan sangat setuju, 39 responden (49\%) menyatakan setuju, dan 6 responden $(8 \%)$ menyatakan kurang setuju. Oleh karena itu dapat dibuat kesimpulan bahwa produk dan jasa yang ditawarkan oleh BRI sebesar 92\%telah sesuai dengan keinginan dan kebutuhan para debiturnya. Sedangkan sisanya sebesar $8 \%$ menunjukkan bahwa terdapat keinginan dan kebutuhan debitur yang belum disediakan oleh BRI Somba Opu. Hal ini perlu dikaji dan di cermati karena merupakan peluang bisnis bagi BRI Somba Opu.

\section{Variabel Loyalitas Debitur}

Berdasarkan rata-rata penilaian dari 80 responden terhadap keenam indikator yang menentukan bentuk dari variabel loyalitas debitur, terdapat 37 responden (46\%) menyatakan sangat setuju, 40 responden (50\%) menyatakan setuju, dan 3 responden (4\%) menyatakan kurang setuju. Oleh karena itu dapat dibuat kesimpulan mengenai tingkat loyalitas debitur, yaitu bahwa 96\% debitur memiliki tingkat loyalitas yang tinggi terhadap fasilitas pinjaman/kredit di BRI Somba Opu, dan hanya 4\% debitur yang tidak loyal.

\section{a. Uji Validitas}

Uji Validitas adalah prosedur untuk memastikan apakah kuesioner yang akan dipakai untuk mengukur variabel penelitian valid atau tidak. 
AL-MASHRAFIYAH: Jurnal Ekonomi, Keuangan, dan Perbankan Syariah Volume 2, Nomor 2, Oktober 2018

Tabel 5. Hasil Uji Validitas

\begin{tabular}{|c|c|c|c|c|}
\hline Konstruk & Item & r hitung & r tabel & Kevalidan \\
\hline \multirow[t]{9}{*}{ Financial Bonds $\left(\mathrm{X}_{1}\right)$} & Butir 1 & 0,775 & 0,232 & valid \\
\hline & Butir 2 & 0,530 & 0,232 & valid \\
\hline & Butir 3 & 0,675 & 0,232 & valid \\
\hline & Butir 4 & 0,717 & 0,232 & valid \\
\hline & Butir 5 & 0,652 & 0,232 & valid \\
\hline & Butir 6 & 0,560 & 0,232 & valid \\
\hline & Butir 7 & 0,591 & 0,232 & valid \\
\hline & Butir 8 & 0,818 & 0,232 & valid \\
\hline & Butir 9 & 0,367 & 0,232 & valid \\
\hline \multirow[t]{9}{*}{ Social Bonds $\left(\mathrm{X}_{2}\right)$} & Butir 1 & 0,549 & 0,232 & valid \\
\hline & Butir 2 & 0,689 & 0,232 & valid \\
\hline & Butir 3 & 0,603 & 0,232 & valid \\
\hline & Butir 4 & 0,716 & 0,232 & valid \\
\hline & Butir 5 & 0,731 & 0,232 & valid \\
\hline & Butir 6 & 0,762 & 0,232 & valid \\
\hline & Butir 7 & 0,349 & 0,232 & valid \\
\hline & Butir 8 & 0,676 & 0,232 & valid \\
\hline & Butir 9 & 0,410 & 0,232 & valid \\
\hline \multirow{9}{*}{$\begin{array}{c}\text { Customization Bonds } \\
\qquad\left(\mathrm{X}_{3}\right)\end{array}$} & Butir 1 & 0,475 & 0,232 & valid \\
\hline & Butir 2 & 0,593 & 0,232 & valid \\
\hline & Butir 3 & 0,588 & 0,232 & valid \\
\hline & Butir 4 & 0,750 & 0,232 & valid \\
\hline & Butir 5 & 0,805 & 0,232 & valid \\
\hline & Butir 6 & 0,759 & 0,232 & valid \\
\hline & Butir 7 & 0,711 & 0,232 & valid \\
\hline & Butir 8 & 0,697 & 0,232 & valid \\
\hline & Butir 9 & 0,551 & 0,232 & valid \\
\hline \multirow{9}{*}{ Structural Bonds $\left(\mathrm{X}_{4}\right)$} & Butir 1 & 0,660 & 0,232 & valid \\
\hline & Butir 2 & 0,677 & 0,232 & valid \\
\hline & Butir 3 & 0,760 & 0,232 & valid \\
\hline & Butir 4 & 0,599 & 0,232 & valid \\
\hline & Butir 5 & 0,536 & 0,232 & valid \\
\hline & Butir 6 & 0,611 & 0,232 & valid \\
\hline & Butir 7 & 0,775 & 0,232 & valid \\
\hline & Butir 8 & 0,828 & 0,232 & valid \\
\hline & Butir 9 & 0,711 & 0,232 & valid \\
\hline \multirow[t]{6}{*}{ Loyalitas $\left(\mathrm{Y}_{1}\right)$} & Butir 1 & 0,509 & 0,232 & valid \\
\hline & Butir 2 & 0,499 & 0,232 & valid \\
\hline & Butir 3 & 0,757 & 0,232 & valid \\
\hline & Butir 4 & 0,692 & 0,232 & valid \\
\hline & Butir 5 & 0,646 & 0,232 & valid \\
\hline & Butir 6 & 0,648 & 0,232 & valid \\
\hline
\end{tabular}

Sumber: Data Primer Diolah Tahun 2017 
Muhammad Taufiq. Implikasi Relationship Marketing...

Tabel tersebut memperlihatkan bahwa seluruh item pernyataan memiliki nilai koefisien korelasi positif dan lebih besar dari pada r-tabel. Hal ini berarti bahwa data yang diperoleh telah valid dan dapat dilakukan pengujian data lebih lanjut.

\section{b. Uji Realibilitas}

Uji reliabilitas digunakan untuk mengukur suatu kuesioner yang merupakan indikator dari variabel atau konstruk. Suatu kuisioner dikatakan reliabel atau handal jika jawaban seseorang terhadap pernyataan adalah konsisten atau stabil dari waktu ke waktu. Uji reliabilitas data dilakukan dengan menggunakan metode Alpha Cronbach yakni suatu instrumen dikatakan reliabel bila memiliki koefisien keandalan reabilitas sebesar 0,60 atau lebih.

Tabel 6. Hasil Uji Reliabilitas

\begin{tabular}{clcc}
\hline No & \multicolumn{1}{c}{ Instrumen Penelitian } & Cronbach's Alpha & Keterangan \\
\hline 1 & Financial Bonds $\left(\mathrm{X}_{1}\right)$ & 0,767 & Reliabel \\
2 & Social Bonds $\left(\mathrm{X}_{2}\right)$ & 0.760 & Reliabel \\
3 & Customization Bonds $\left(\mathrm{X}_{3}\right)$ & 0,770 & Reliabel \\
4 & Structural Bonds $\left(\mathrm{X}_{4}\right)$ & 0,774 & Reliabel \\
5 & Loyalitas $\left(\mathrm{Y}_{1}\right)$ & 0,774 & Reliabel \\
\hline
\end{tabular}

Sumber : Data Primer Diolah, Tahun 2017

Tabel tersebutdiatas menunjukkan bahwa nilai cronbach's alpha dari semua variabel lebih besar dari 0,60, sehingga dapat disimpulkan bahwa instrumen dari kuesioner yang digunakan untuk menjelaskan variabel Financial Bonds, Social Bonds, Customization Bonds, Structural Bonds dan Loyalitasdinyatakan handal atau dapat dipercaya sebagai alat ukur variabel.

\section{B. Analisis Regresi Linier Berganda}

Hasil pemrosesan data dengan menggunakan program SPSS tersaji data dalam tabel berikut :

Tabel 7. Hasil Analisis Regresi Linier Berganda

\begin{tabular}{lccc}
\hline \multicolumn{1}{c}{ Variabel } & B & $\boldsymbol{t}$ Hitung & Sig \\
\hline Loyalitas $\left(\mathrm{Y}_{1}\right)$ & 1,129 & 3,651 & 0,000 \\
Financial Bonds $\left(\mathrm{X}_{1}\right)$ & 0,018 & 0,140 & 0,889 \\
Social Bonds $\left(\mathrm{X}_{2}\right)$ & 0,198 & 1,692 & 0,095 \\
Customization Bonds $\left(\mathrm{X}_{3}\right)$ & 0,268 & 2,076 & 0,041 \\
Structural Bonds $\left(\mathrm{X}_{4}\right)$ & 0,283 & 2,670 & 0,009 \\
\hline R Square & & & 0,615 \\
R Correlation & & & 0,784 \\
Constant & & & 1,129 \\
F Ratio & & & 29,922 \\
F-Tabel & & & 1,455 \\
t- Tabel & & & 1,991 \\
\hline
\end{tabular}

Sumber: Data Primer Diolah, Tahun 2017

Berdasarkan perhitungan analisis regresi linier berganda dengan bantuan SPSS, diperoleh nilai koefisien persamaan regresi, yaitu $\alpha, \beta_{1}, \beta_{2}, \beta_{3}, \beta_{4}$ masing-masing dengan nilai 1,$129 ; 0,018 ; 0,198 ; 0,268 ; 0,283$, sehingga persamaan regresi menjadi sebagai berikut :

$$
Y=1,129+0,018 X_{1}+0,198 X_{2}+0,268 X_{3}+0,283 X_{4}
$$




\section{AL-MASHRAFIYAH: Jurnal Ekonomi, Keuangan, dan Perbankan Syariah}

Volume 2, Nomor 2, Oktober 2018

\section{Uji F}

Analisis dari hasil uji $\mathrm{F}$ ini dimaksudkan untuk membuktikan kebenaran dari hipotesis pertama penelitian ini, yakni "Strategi Relationship Marketing (Financial Bonds, Social Bonds, Customization Bonds, dan Structural Bonds) secara bersama-sama berpengaruh terbadap tingkat loyalitas debitur kredit komersial PT. Bank Rakyat Indonesia (Persero) Tbk. Kantor Cabang Makassar Somba Opu'.

Hasil perhitungan model analisis regresi linier berganda dengan bantuan program SPSS menunjukkan, F ratio adalah sebesar 29,922, lebih besar dari F tabel yaitu sebesar 1,455, yang berarti koefisien regresi adalah signifikan. Hal ini menunjukkan bahwa pada taraf signifikasi $\alpha$ $=0,05$, variabel Strategi Relationship Marketing (Financial Bonds, Social Bonds, Customization Bonds, dan Structural Bonds) secara bersama-sama berpengaruh terbadap tingkat loyalitas debitur kredit komersial PT. Bank. Rakyat Indonesia (Persero) Tbk. Kantor Cabang Makassar Somba Opu. Dengan demikian dapat simpulkan bahwa hipotesis pertama dalam penelitian ini diterima atau terbukti kebenarannya.

Kemudianuntuk melihat seberapa besar pengaruh (kontribusi) variabel bebas secara bersama-sama terhadap variabel terikat, dapat dilihat dari besarnya koefisien determinasi ganda $\left(\mathrm{R}^{2}\right)$ atau $\mathrm{R}$ Squareyaitu sebesar 0,615. Hal ini menunjukkan bahwa seluruh variabel bebas yang terdiri dari Financial Bonds, Social Bonds, Customization Bonds, dan Structural Bonds secara bersamasama berpengaruh sebesar 0,615 atau 61,5\% terhadap tingkat loyalitas debitur kredit komersial PT. Bank Rakyat Indonesia (Persero) Tbk. Kantor Cabang Makassar Somba Opu. Sedangkan sisanya sebesar 0,385 atau 38,5\% dipengaruhi oleh faktor lain yang tidak diteliti.

Selanjutnya untuk mengetahui indikasi hubungan variabel bebas secara bersama-sama dengan variabel terikatnya, dapat dilihat dari besarnya nilai koefisien regresi multiple $(\mathrm{R}$ Correlation). Hasil perhitungan menunjukkan, besarnya nilai koefisien regresi multiple ( $\mathrm{R}$ Correlation) sebesar 0,784. Hal ini menggambarkan adanya indikasi hubungan yang kuat antara variabel bebas yang terdiri dari dari Financial Bonds, Social Bonds, Customization Bonds, dan Structural Bonds dengan tingkat loyalitas debitur kredit komersial PT. Bank Rakyat Indonesia (Persero) Tbk. Kantor Cabang Makassar Somba Opu.

\section{Uji Partial (Uji t)}

Analisis dari hasil uji t ini dimaksudkan untuk membuktikan kebenaran dari hipotesis kedua penelitian ini, yakni, yaitu "Dari ke-4 (empat) strategi Relationship Marketing tersebut di atas, Social Bonds memiliki pengaruh dominan terhadap tingkat loyalitas debitur kredit komersial PT. Bank Rakyat Indonesia (Persero) Tbk. Kantor Cabang Makassar Somba Opu”.

Tabel 8.Hasil Perhitungan Uji t SPSS

\begin{tabular}{lccccc}
\hline \multicolumn{1}{c}{ Variabel } & t-hitung & t-tabel & Partial $\mathbf{r}$ & ${\text { Partial } \mathbf{r}^{2}}$ & Keterangan \\
\hline Financial Bonds $\left(\mathrm{X}_{1}\right)$ & 0,140 & 1,991 & 0,676 & 0,457 & Tidak Signifikan \\
Social Bonds $\left(\mathrm{X}_{2}\right)$ & 1,692 & 1,991 & 0,663 & 0,440 & Tidak Signifikan \\
Customization Bonds $\left(\mathrm{X}_{3}\right)$ & 2,076 & 1,991 & 0,737 & 0,543 & Signifikan \\
Structural Bonds $\left(\mathrm{X}_{4}\right)$ & 2,670 & 1,991 & 0,720 & 0,518 & Signifikan \\
\hline
\end{tabular}

Sumber : Data Primer Diolah, Tahun 2017

Nampak pada tabel di atas bahwa variabel Customization Bonds mempunyai koefisien korelasi yang paling besar dibandingkan variable-variabel lainnya. Sehingga variabel 
Muhammad Taufiq. Implikasi Relationship Marketing...

Customization Bonds dinilai paling signifikan (dominan) berpengaruh terhadap tingkat loyalitas debitur kredit komersial PT. Bank Rakyat Indonesia (Persero) Tbk. Kantor Cabang Makassar Somba Opu.

a. Hubungan variabel Financial Bonds terhadap tingkat loyalitas debitur kredit komersial.

Nilai t- hitung variabel Financial Bonds terhadap tingkat loyalitas debitur kredit komersial sebesar 0,140 lebih kecil dari t- tabel sebesar 1,991. Dengan demikian $\mathrm{H}_{0}: \beta_{1}=0$, yang berarti variabel independent ke-1 (variabel Financial Bonds) tidak memiliki pengaruh signifikan terhadap tingkat loyalitas debitur kredit komersial PT. Bank Rakyat Indonesia (Persero) Tbk. Kantor Cabang Makassar Somba Opu.

Kemudian berdasarkan hasil pengolahan data terlihat bahwa besarnya kekuatan hubungan (korelasi) antara variabel Financial Bondsterhadap tingkat loyalitas debitur kredit komersial PT. Bank Rakyat Indonesia (Persero) Tbk. Kantor Cabang Makassar Somba Opu adalah sebesar 0,676(partial r). Sedangkan dengan melihat $r^{2}$ sebesar 0,457 maka dapat dijelaskan bahwa variabel FinancialBonds mempunyai kontribusi terhadap tingkat loyalitas debitur kredit komersial sebesar 45,7\%.

b. Hubungan variabel Social Bonds terhadap tingkat loyalitas debitur kredit komersial.

Nilai t - hitung variabel Social Bonds terhadap tingkat loyalitas debitur kredit komersial sebesar 1,692 lebih besar dari $\mathrm{t}$ - tabel sebesar 1,991. Dengan demikian $\mathrm{H}_{0}: \beta_{2}=0$, yang berarti variabel independent ke-2 (variabel Social Bonds) tidak memiliki pengaruh signifikan terhadap tingkat loyalitas debitur kredit komersial PT. Bank Rakyat Indonesia (Persero) Tbk. Kantor Cabang Makassar Somba Opu.

Kemudian berdasarkan hasil pengolahan data terlihat bahwa besarnya kekuatan hubungan (korelasi) antara variabel Social Bondsterhadap tingkat loyalitas debitur kredit komersial PT. Bank Rakyat Indonesia (Persero) Tbk. Kantor Cabang Makassar Somba Opu sebesar 0,663 (partial r). Sedangkan dengan melihat $\mathrm{r}^{2}$ sebesar 0,440 maka dapat dijelaskan bahwa variabel Social Bonds mempunyai kontribusi terhadap tingkat loyalitas debitur kredit komersial sebesar $44 \%$.

c. Hubungan variabel Customization Bonds terhadap tingkat loyalitas debitur kredit komersial.

Nilai t - hitung variabel Social Bonds terhadap tingkat loyalitas debitur kredit komersial sebesar 2,076 lebih besar dari $\mathrm{t}$ - tabel sebesar 1,991. Dengan demikian $\mathrm{H}_{0}: \beta_{3} \neq 0$, yang berarti variabel independent ke-3 (variabel Customization Bonds) memiliki pengaruh signifikan terhadap tingkat loyalitas debitur kredit komersial PT. Bank Rakyat Indonesia (Persero) Tbk. Kantor Cabang Makassar Somba Opu.

Hasil perhitungan analisis regresi linier berganda menunjukkan bahwa koefisien regresi determinan partial untuk variabel Customization Bonds adalah 0,268 dan bertanda positif (hubungan searah). Hal ini berarti bahwa dengan kenaikan sebesar 1 satuan terhadap Customization Bond akan memberikan pengaruh positif (searah) terhadap variabel dependen (Loyalitas) sebesar 0,268 satuan.

Berdasarkan hasil pengolahan data terlihat bahwa besarnya hubungan variabel Customization Bondsterhadap tingkat loyalitas debitur kredit komersial PT. Bank Rakyat Indonesia (Persero) Tbk. Kantor Cabang Makassar Somba Opu sebesar 0,737 (partial r). Sedangkan dengan melihat $\mathrm{r}^{2}$ sebesar 0,543 maka dapat dijelaskan bahwa variabel Customization Bonds mempunyai kontribusi terhadap tingkat loyalitas debitur kredit komersial sebesar 54,3\%.

d. Hubungan variabel Structural Bonds terhadap tingkat loyalitas debitur kredit komersial.

Nilai $\mathrm{t}$ - hitung variabel Structural Bonds terhadap tingkat loyalitas debitur kredit komersial sebesar 2,670 lebih besar dari $\mathrm{t}$ - tabel sebesar 1,991. Dengan demikian $\mathrm{H}_{0}: \beta_{4} \neq 0$, yang berarti 
variabel independent ke-3 (variabel Structural Bonds) memiliki pengaruh signifikan terhadap tingkat loyalitas debitur kredit komersial PT. Bank Rakyat Indonesia (Persero) Tbk. Kantor Cabang Makassar Somba Opu.

Hasil perhitungan analisis regresi linier berganda menunjukkan bahwa koefisien regresi determinan partial untuk variabel Structural Bonds adalah 0,283 dan bertanda positif (hubungan searah). Hal ini berarti bahwa dengan kenaikan sebesar 1 satuan terhadap Structural Bondsakan memberikan pengaruh positif (searah) terhadap variabel dependen (Loyalitas) sebesar 0,283 satuan.

Berdasarkan hasil pengolahan data terlihat bahwa besarnya hubungan variabel Structural Bondsterhadap tingkat loyalitas debitur kredit komersial PT. Bank Rakyat Indonesia (Persero) Tbk. Kantor Cabang Makassar Somba Opu sebesar 0,720 (partial r). Dengan melihat $\mathrm{r}^{2}$ sebesar 0,518 maka dapat dijelaskan bahwa variabel Structural Bonds mempunyai kontribusi terhadap tingkat loyalitas debitur kredit komersial sebesar 51,8\%.

Dari keempat variabel Relationship Marketing, yang memiliki pengaruh paling besar terhadap tingkat loyalitas debitur adalah variabel $\mathrm{X}_{3}$ (Customization Bond) dengan persentase pengaruh sebesar 54,3\%. Berturut-turut $\mathrm{X}_{4}$ (Structural Bond) sebesar 51,8 \%, kemudian $\mathrm{X}_{1}$ (Financial Bond) sebesar 45,7\%, terakhir adalah $\mathrm{X}_{2}$ (Social Bond) dengan persentase pengaruh paling kecil yaitu $44 \%$.

Melihat hasil ini, berarti hipotesis kedua yang diajukan dalam penelitian ini bahwa dari ke-4 (empat) strategi Relationship Marketing tersebut di atas, Social Bonds memiliki pengaruh dominan terhadap tingkat loyalitas debitur kredit komersial PT. Bank Rakyat Indonesia (Persero) Tbk. Kantor Cabang Makassar Somba Opu tidak dapat diterima atau tidak terbukti kebenarannya.

Ada beberapa pendapat dari peneliti mengenai mengapa hipotesis kedua berbeda dengan hasil penelitian :

1. BRI saat ini telah berusia 111 tahun, dianggap perusahaan yang sudah sangat dewasa, sehingga diduga bahwa BRI telah memiliki ikatan sosial yang kuat dengan para debiturnya, yang menjadi dasar penentuan dari hipotesis kedua (Social Bonds) dari penelitian ini. Tetapi berdasarkan hasil penelitian dapat disimpulkan bahwa karena usia BRI yang sudah sangat dewasa, BRI dianggap telah membangun Customer Intimacy (Indikator dari Customization Bonds) dengan para debiturnya, karena dengan adanya unit-unit kerja yang sampai ke pelosok-pelosok Desa atau Kelurahan, yang jumlahnya hingga saat ini telah mencapai 4.447 Unit Kerja yang membuat hubungan semakin dekat dengan para debiturnya.

2. Segmen pasar yang dikelola oleh BRI adalah segmen mikro, kecil, dan menengah (UMKM). Saat ini segmen tersebut dianggap paling cocok dengan kondisi ekonomi dan sektor usaha. Terbukti ketika krisis ekonomi tahun 1998 terjadi, segmen ini mampu bertahan dan berhasil melewati hantaman krisis ekonomi. Selain itu, pada tahun 2005 BRI mendapat penghargaan dari PBB sebagai bank yang mengelola segmen mikro dengan sangat baik. Karena kemampuan BRI mengelola segmen UMKM ini, dan penulis menganggap BRI telah berhasil membangun Mass Customization (Indikator dari Customization Bonds).

3. BRI secara konsisten berupaya untuk meningkatkan kualitas layanan dan teknologi perbankan yang inovatif, yang memudahkan bagi para debiturnya menggunakan dan meng-akses layanan dengan mudah (Indikator dari Customization Bonds), terbukti semakin banyak Kantor Unit BRI yang telah OnLine di seluruh pelosok nusantara. 
Muhammad Taufiq. Implikasi Relationship Marketing...

\section{PENUTUP}

Hasil penelitian ini menunjukan bahwa variabel strategi Relationship Marketing (Financial Bonds, Social Bonds, Customization Bonds, dan Structural Bonds) secara bersama-sama berpengaruh positif terhadap tingkat loyalitas debitur kredit komersial PT. Bank Rakyat Indonesia (Persero) Tbk. Kantor Cabang Makassar Somba Opu. Dengan demikian hipotesis pertama diterima atau terbukti kebenarannya. Kemudian Berdasarkan hasil analisis Uji t yang dilakukan, didapatkan hasil bahwa variabel Customization Bonds memberikan pengaruh paling kuat (dominan)terhadap tingkat loyalitas debitur kredit komersial PT. Bank Rakyat Indonesia (Persero) Tbk. Kantor Cabang Makassar Somba Opu, kemudian diikuti berturut-turut oleh Structural Bonds, Financial Bonds, dan Social Bonds. Dengan demikian, hipotesis kedua tidak terbukti kebenarannya.

Dari simpulan di atas maka implementasi hasil :

1. Di dalam menerapkan strategi Relationship Marketing untuk produk kredit komersial di PT. Bank Rakyat Indonesia (Persero) Tbk. Kantor Cabang Makassar Somba Opu, dipandang perlu untuk memperhatikan variabel-variabel Relationship Marketing, yaitu Financial Bonds, Social Bonds, Customization Bonds, dan Structural Bonds.Dan untuk variabel Customization Bonds dapat menjadi pertimbangan utama di dalam menerapkan strategi Relationship Marketing. Namun demikian, variabel-variabel lainnya, yaitu Financial Bonds, Social Bonds, dan Structural Bonds juga tetap harus menjadi pertimbangan.

2. Untuk penelitian selanjutnya, penulis menyarankan untuk memperluas lingkup penelitian pada Kantor Cabang BRI lainnya untuk mendapatkan hasil yang lebih baik.

\section{DAFTAR PUSTAKA}

Aryan, Hellas Limited. (2005), Relationship Marketing : Understanding and Implementing the Concept, IBRC, Athens.

Atjo, Muh. Akbar. (2003), Pengaruh Dimensi Kualitas Layanan Terhadap Tingkat Kepuasan Pelanggan SIM Card GSM Kartu Halo Telkomsel Regional Sulawesi Malirja (Unit Pelayanan Grapari Makassar), PPMM UNHAS, Makassar.

Awaluddin, Murtiadi, and Sukmawati Sukmawati. "Implikasi Theory Of Reasoned Action Dan Etika Dalam Meningkatkan Kepatuhan Wajib Pajak Kendaraan Bermotor Melalui Niat." Al-Mashrafiyah (Jurnal Ekonomi, Keuangan dan Perbankan Syariab), Vol.1.No.1 Oktober 2017.

Chan, Syafruddin. (2003), Relationship Marketing (Inovasi Pemasaran yang membuat Pelanggan bertekuk lutut), PT. Gramedia Pustaka Utama, Jakarta.

Gani, Nuraeni. "Determinan Kinerja Karyawan Bank Sulselbar Syariah." Al-Mashrafiyah (Jurnal Ekonomi, Kenangan dan Perbankan Syariab), Vol. 1. No.2 April 2018.

Hutasuhut, Arman D. (2004), Strategi Pemasaran Berorientasi Hubungan Dengan Pelanggan, Jurnal Ilmiah Manajemen \& Bisnis, Vol.04 No.01 April 2004.

Lovelock, Christopher H. dan Wright, Lauren K. (2005), Manajemen Pemasaran Jasa, PT. Indeks Kelompok Gramedia, Jakarta

Priyadi, (2007), Analisis Faktor-Faktor Yang Mempengarubi Keputusan Konsumen Dalam Memilih Produk Tabungan Mudharabah Di Bank BRI Syariah Makassar, MM UNHAS, Makassar 
AL-MASHRAFIYAH: Jurnal Ekonomi, Keuangan, dan Perbankan Syariah Volume 2, Nomor 2, Oktober 2018

Taylor, Graham K. (1995), An Investigation Into the Potential Aplication of Relatonship Marketing in the British House Building Industry, High Wycombe, Bucks HP13 5ER, England.

Tjiptono, Fandy. (2005), Pemasaran Jasa, Banyumedia Publishing, Malang.

Yusuf, Ahmad Muhlis, M.Mgt. (2006), Relationship Marketing, Warta JWC, Vol.8/IV/Agustus/2006, Universitas Bina Nusantara, Jakarta Selatan. 